\title{
"Letter to the Editor: Surgical Treatment of Primary Cardiac Tumors in the Contemporary era: A single-centre Analysis."
}

Taha Nadeem ${ }^{1}$, Fatima Tanveer ${ }^{1}$, and Mahima Khatri ${ }^{2}$

${ }^{1}$ Allama Iqbal Medical College

${ }^{2}$ Dow University of Health Sciences

March 3, 2022

TITLE PAGE

TOPIC : "Letter to the Editor: Surgical Treatment of Primary Cardiac Tumors in the Contemporary era: A single-centre Analysis."

ARTICLE TYPE : LETTER TO THE EDITOR

CORRESPONDANCE :1. Name: Taha Nadeem

Institute : ALLAMA IQBAL MEDICAL COLLEGE,LAHORE,PAKISTAN

Contact : +923107033138 E-mail : Tahamodellian786@gmail.com

Address : House\# 451, Jinnah Colony, Faisalabad,Pakistan

CO-AUTHORS: 2. Name : Fatima Tanveer

Institute : ALLAMA IQBAL MEDICAL COLLEGE, LAHORE, PAKISTAN.

Contact : +923468789469 E-mail : Fatimatanveer990@gmail.com

Address : House\#101,Street 10,Block C, Canal Town, Gujranwala ,Pakistan.

3. Mahima Khatri

Contact: +923472651872 Email: mahimakhatri12333@gmail.com

Institute: Dow University of Health Sciences, Karachi

Address: bridge view apartment, frere town, clifton block 8 karachi, 75600

Word count: 442

Conflict of interest: None

Declaration: None

Acknowledgment: None

Letter:

To the editor

We have read with great sincerity the article, "Surgical treatment of primary cardiac tumors in the contemporary era: A single Centre analysis," by Matteo Matteucci MD et al. ${ }^{1}$ It was a pleasure for us to read 
the concisely written article, and we congratulate the authors for their excellent efforts, but we have few concerns regarding the article which we would like to mention here.

The authors did not highlight some significant non-myxoma tumors like fibroma, hemangioma, and pheochromocytoma. ${ }^{2}$ These tumors do not have a good prognosis like myxoma, so the percentage of morbidity and mortality after resection of primary tumors could vary, as mentioned in the article. Moreover, the authors mentioned cerebral embolic symptoms like a stroke but did not highlight peripheral embolic events and constitutional symptoms. ${ }^{(2,5)}$ Likewise, talking about the final message of the article, which states that "Surgical resection of benign tumors is safe and complete excision results in no recurrence especially for Myxoma" But the Authors did not mention about Myxoma-Myxofibrosarcoma transformations that occur with a frequency of $1.3 \%{ }^{3}$ This finding could change the outcomes of the study. Third, the authors mentioned the relation of mortality with tumor Histology, but there was no reference of characteristics such as Symptomology, Age, and Gender. This article states that Surgical resection of all benign tumors have a reasonable survival rate. However, some research shows that only resection of myxomas has good survival characteristics compared to other benign histological variants whose results vary significantly in different age or gender groups. Moreover, resectioning fibromas, papillary fibroelastosis, and lipomas have poor survival characteristics. ${ }^{3}$ The survival rate after resection of these tumors varies in different age groups as these tumors have a poor prognosis at a younger age.

Fourth, the authors did not highlight resection of primary malignant tumors, most commonly angiosarcoma. ${ }^{4}$ Although these tumors have a very poor prognosis, research shows that patients with a radical resection at first surgery had more prolonged survival than patients with partial resection. The mean survival is better in Men than in Women.

Lastly, the authors did not explain the reason for early and late morbidity and mortality. At the same time, some researches proved that early morbidity and mortality after tumor resection was due to arrhythmias, heart block, and pericardial effusion, and late morbidity and mortality was due to arrhythmia and heart block. In operation techniques, the authors mentioned right and left atriotomy but did not highlight pulmonary lobectomy in some operating techniques. ${ }^{5}$ These new findings should be an important concern as some benign histological variants of myxoma have poor prognosis so it should not be generalized that all primary cardiac tumors have safe results.

\section{References:}

1. Matteucci M, Ferrarese S, Mantovani V, Ronco D, Torchio F, Franzosi C, Marazzato J, De Ponti R, Lorusso R, Beghi C. Surgical treatment of primary cardiac tumors in the contemporary era: A singlecentre analysis. J Card Surg. 2021 Oct;36(10):3540-3546. doi: 10.1111/jocs.15813. Epub 2021 Jul 12. PMID: 34254361; PMCID: PMC8518736.

2. Kamiya H, Yasuda T, Nagamine H, Sakakibara N, Nishida S, Kawasuji M, Watanabe G. Surgical treatment of primary cardiac tumors: 28 years' experience in Kanazawa University Hospital. Jpn Circ J. 2001 Apr;65(4):315-9. doi: 10.1253/jcj.65.315. PMID: 11316130.

3. Elbardissi AW, Dearani JA, Daly RC, Mullany CJ, Orszulak TA, Puga FJ, Schaff HV. Survival after resection of primary cardiac tumors: a 48-year experience. Circulation. 2008 Sep 30;118(14 Suppl):S715. doi: 10.1161/CIRCULATIONAHA.107.783126. PMID: 18824772.

4. Pacini D, Careddu L, Pantaleo A, Parolari A, Leone O, Daprati A, Gargiulo GD, Di Bartolomeo R. Primary malignant tumors of the heart: Outcomes of the surgical treatment. Asian Cardiovasc Thorac Ann. 2015 Jul;23(6):645-51. doi: 10.1177/0218492315573674. Epub 2015 Feb 18. PMID: 25698795.

5. Centofanti P, Di Rosa E, Deorsola L, Dato GM, Patanè F, La Torre M, Barbato L, Verzini A, Fortunato G, di Summa M. Primary cardiac tumors: early and late results of surgical treatment in 91 patients. Ann Thorac Surg. 1999 Oct;68(4):1236-41. doi: 10.1016/s0003-4975(99)00700-6. PMID: 10543485. 